\title{
Discussion on the Visual Perception of Chinese Characters Based on Neurocognitive Linguistics
}

\section{Discusión sobre la percepción visual de los caracteres chinos basada en la lingüística neurocognitiva}

DOI: $10.32870 /$ mycp.v9i25.625

Hao Chen ${ }^{1}$

\begin{abstract}
This article will study the cognitive nature of Chinese characters and the neurocognitive basis of the visual perception of Chinese characters in Chinese learning through the dismantling of Chinese character components, adopted into the "Relational Network Theory" (RNT) proposed by Sydney Lamb. We will also discuss the neurocognitive basis of zìgăn, 字感 (Bai \& Liu, 2006), GraphoMorphological Awareness of Chinese characters, an abstract concept entangled in the Chinese Character Teaching (сСт), and some of the concepts included in Ausubel' Meaningful Learning Theory, to ground a teaching methodology of the ССт in the Chinese International Teaching (CIT).
\end{abstract}

Keywords: Neurocognitive Linguistics; Relational Network Theory; Meaningful Learning Theory; components of Chinese characters; characteme

\begin{abstract}
Resumen
Este artículo explora la naturaleza cognitiva de los caracteres chinos y la enmarca en la Lingüística Neurocognitiva para versar sobre la percepción visual de los caracteres chinos en el aprendizaje de lengua china, mediante la descomposición de los bùjiàn de los caracteres chinos, adaptada a la Teoría de Redes Relacionales (TRR), planteada por Sydney Lamb. También hablaremos de la base neurocognitiva del zìgăn, 字感 (Bai \& Liu, 2006), Conciencia GrafoMorfológica de los caracteres chinos, un concepto implicado en la Enseñanza de los Caracteres Chinos (ECC), y algunos de los conceptos propuestos en la Teoría del Aprendizaje Significativo de Ausubel, para sentar las bases de una metodología didáctica de la ECC dentro de la Enseñanza Internacional de Chino (EIC).
\end{abstract}

Palabras clave: Lingüística Neurocognitiva; Teoría de Redes Relacionales; Teoría del Aprendizaje Significativo; componentes de los caracteres chinos;

caractema.

Artículo recibido el 28 de marzo de 2019 y dictaminado el 07 de mayo de 2019.

1. Fudan University, College of Foreign Language and Literature. 220 Luan Road, Shanghai, China. 200433 ORCID: https://orcid.org/0000-0002-1848-4635 E-mail: h_chen@fudan.edu.cn 


\section{Introduction}

As pictograms and ideograms, the origin of Chinese characters is related to the cognitive capacities of Chinese ancestors (Chen, 2015, 2017a). By analyzing it, we discovered that $C$ hinese ancestral wisdom had already made a rational interpretation of the cognitive nature underneath the Chinese characters' invention: "to describe the near things via body, to describe the far things via objects" 2 . This depiction can be understood in ways that extend to the most relevant of the cognitive domain: to know firstly the near things, and then, the further ones. The learning of Chinese characters has always been an important part of Chinese Language Teaching (CLT), and it is also a problem that remains unsolved in the CLT. Since Chinese characters consist in one of the learning difficulties in the Chinese language, Chinese Characters Teaching (сст) tends to be a huge obstacle in Teaching Chinese as a Foreign Language (TCFL). This is closely related to the characteristics and attributes of Chinese characters, which first leads to a re-examination of the Chinese character ontology and even to the mysterious origin of Chinese characters. Meanwhile, the International Chinese Teaching Community also produced a method of сст. Combined with the joint efforts of many domestic and foreign scholars, it has been widely accepted that, at present, the teaching of Chinese characters' components, known as bùjiàn, 部件, components, in Chinese International Language Teaching (CIT) is a very effective method. Nevertheless, there is no unanimous comprehension of the components teaching methods, and the traditional Chinese character teaching has been badly influenced by the substitutable input methods produced in the Information Age: the written practice in the early сст have been replaced by the popularization of computer input methods. The phenomenon of "picking pens and forgetting how to write" has induced people once again to worry about triggering a new

2. The phrase is a well-known expression in Shuowenjiezi (Xu, 1963), whose original version is "Gŭ zhě Páoxī shì zhī wàng tiānxià yě, yăng zé guānxiàng yú tiān, fǔ zé guānfă yú dì, guān niăoshòu zhī wén yǔ dì zhī yí, jìn qǔzhū shēn, yuăn qǔzhū wù, yúshì shǐ zuò bāguà, y̌̌ tōng shénmíng zhī dé, yǐ lèi wànwù zhī qíng” 古者庖牺氏之王天下也, 仰则观象于天, 俯则观法于地, 观鸟兽之文与地之 宜, 近取诸身, 远取诸物, 于是始作八卦, 以通神明之德, 以类万物之情, which means “In ancient times, during the Paoxi's government, he looked up to observe the sky and looked down to observe the earth. Observing the traces of the animals and the morphology of the earth, he utilized the corporal elements to describe near things and he utilized the objects to describe far things, thus he created the bagua, the eight symbols, to know the divine virtue, and in this way deduced the reason of the whole universe. 
Chinese character crisis (Chen, 2018). Apparently, it is unavoidable to encounter a writing crisis in ССт. At present, the recognition and decipherment of Chinese characters is not only important in CIT, but also in other fields, such as artificial intelligence. Therefore, this article has turned its attention to discuss the visual perception of Chinese characters from the perspective of Neurocognitive Linguistics and conduct preliminary theoretical research on the perception of Chinese character components on its base, to wrap up some scientific methods in confrontation with the traditional ones in сст. In the following, the Chinese character components teaching will be discussed from the RNT perspective of Neurocognitive Linguistics, the study of Chinese characters' components, and Ausubel's Meaningful Learning Theory.

\section{A componential approach of Chinese characters}

This part starts with a brief introduction to some studies of the components of Chinese characters.

\subsection{Basic concepts related to the components of Chinese characters}

Chinese characters are composed of different parts or constituent units. Generally speaking, these units are considered as components, which, however, can be divided into even smaller units. Scholars have put forward denominations like b̌̌huà 笔画, strokes; bùjiàn, 部件, components; piānpáng 偏旁, parts; bùshǒu, 部首 or zìgèn, 字根, radicals, etc., to describe them. Hence, the explanation of these concepts.

Strokes are the minimal units of Chinese characters and their constituent components, which are larger units but smaller than characters themselves. For example, the character lā, 拉, to pull, is composed by the component shǒu, $f$, hand, and the component $l i$, 立, to stand. Components can be subclassified into two groups: the independent ones and the dependent ones. The first ones can compose independently a character without incorporation of other components, e.g., the character shǒu, 手, hand, which can be a character, an independent component, and one of the components of other characters, e.g., the character ná, 拿, to catch. The dependent ones are components that cannot form a single character, e.g., the component căo, \#, grass, the component shǒu, f, hand, etc. Accordingly, as for some complex characters, there can be more than two components. For example, the character $z h \grave{l}$, 指, to indicate, are 
formed by the component shǒu, f, hand, and the component zhĭ, 旨, to aim, because at the first dismantling level, the component shǒu, f, hand, is well known, whereas the component zhĭ, 旨, to aim, in turn, is composed of the component $b \grave{l}$, 七, dagger, and the component $r \grave{\imath}$, 日, sun, therefore we will say that the character $z h \grave{l}$, 指, to indicate, has altogether three components: the component shŏu, f, hand, the component br̆, 七, dagger, and the component rì, 日, sun, of which the component shŏu, f, hand, and the component zhĭ, 旨, to aim, belong to the first level, while the component bř, 七, dagger, and the component $r i$, 日, sun, belong to the second level.

Parts are known as special components because in ancient times Chinese characters were only divided for once and it turned out that there were two opposite parts: one on the left side, another on the right. And there wouldn't be further subdivision even though one of the parts in question was still separable. Accordingly, the character zhl̆, 指, to indicate, has only two parts: the part shǒu, f, hand, and the part zhĭ, 旨, to aim. We see that the parts of the characters can be the first level components.

The concept of radicals appeared in the classic Shuowenjiezi (Xu, 1963), whose author Xǔ Shèn, 许慎, Xu Shen, extracted the identical constituent parts from $C$ hinese characters and called them radicals. Hence, for characters such as zhĭ, 指, to indicate, bă, 把, to grip, dă, 打, to fight, tí, 提, to catch, lā, 拉, to pull, and kòu, 扣, button, whose common part is the shǒu, f, hand, we take for the component shǒu, f, hand, as their radical part. Currently, in the majority of dictionaries, it is preferred to use radicals to sort characters and offer users a way to localize efficiently the right ones. Radicals are, in general, semantic parts of the characters. They are articles for lexicographical use to classify Chinese characters.

One of the most elementary and important constituent parts of a character is named root. It is the basic unit of a character, which has a relatively fixed structure formed by several strokes. The study of the roots of characters can also be traced back to Xu Shen, followed by many modern experts in the science of ancient Chinese characters such as Tan Lan, Qiu Xigui, Li Xueqin, etc. Apart from the academic studies, roots form the most fundamental pieces or units of an input type of computer keyboard called wǔbř, 五笔, literally as five strokes. With the help of this type, Chinese people can type characters in computer texts more efficiently. The keyboard marked with wubi was, at one time, substituent and more profitable of the input type compared with pinyin, since the latter is sorted out from the phonetic transcription of Chinese 
characters while the former is valued from their morphological structure. About 20 years ago, there were wubi courses everywhere because to master it a training was required, even a root chart was formulated to help memorize their corresponding positions on keyboard. However, due to the complexity of its use and training, many younger generations, those who have enough knowledge of the phonetic transcription of each character, no longer want to complicate the typing by mastering wubi.

In short, we have several ways to categorize the components of Chinese characters, however, so many criteria for such categorization have made the classification even more complicated, since we can denominate as component any constituent part of a character unless it is a stroke. Yet sometimes a stroke like $y \bar{i}$, 一, one, can be also considered as component, e.g., in the character dàn, 旦, dawn. Ambiguities of this type are not scarce: the diăn, ', point, in the sháo, 勺, spoon, the piě, J , broom, in the yìn, J胤, offspring, etc. Besides, frequently when we refer to a compositional piece of a character, we have to come up with a more appropriate term among stroke, component, part, radical or root, since these are all components. Furthermore, the components themselves are subclassified, so that root can be a component of any level. The nomenclative issue noticed here should be teased apart with a more integrative componential study of Chinese characters.

\subsection{The componential studies of Chinese characters}

The first componential study of Chinese characters can be traced back to the classic book Xiăoxué, 小学, small study (Chen, 2017b). Thereon, it has culminated in the book Shuōwénjiězì, 说文解字, Shuowenjiezi (Xu, 1963), which literally means explaining graphs and analyzing characters. Referring to the componential study, 540 radicals are taken into account for the first time. However, in respect of ССт, our attention will be focused instead on the study of the components called bùjiàn, 部件, component. It should be said that, according to different attributes and functionalities as we've discussed above, bùjiàn, which means pieces or constituent units of an object, in this case, Chinese characters, are subdivided into parts, radicals, roots, etc., classificatory terms that share certain characteristics in common.

At present, the researchers of the componential studies of Chinese characters are mainly domestic scholars (Chen, 2017b). Having taken a literature review of some important studies, we believe that $\mathrm{Wu}$ Liwen's approach $(\mathrm{Wu}$, 
2014) on the dismantling of Chinese characters' components deserves our attention.

\subsection{A brief introduction of characteme}

The study of Chinese characters has a long history. Nowadays, it has become an area of interest for academics and students. Hence, it is necessary to come up with a more unitary and precise term to highlight the scientific study of Chinese characters, which can be applied to a specific study dedicated to CCT, such as the study of zigăn 字感, Grapho-Morphological Awareness (GMA) (Marcos, 2010; Sánchez, 2013) of the Chinese characters, an exclusive concept included in the learning of the Chinese characters. Besides, a simple mention of component or part gives the sensation that it dispenses of a uniform and concise terminology. Therefore, sometimes it is required radical or phonetic part to specify each specific case: in the character mù, 沐, to bathe, for example, the shuí,, , water, is a radical part (or simply radical) while the mù, 木, wood, is the phonetic part (or phonetic component). Why are there so many terms to denominate the same piece of a character that sometimes overlap each other to designate the same thing but are not really as equals in meaning? This complexity will probably be solved with the approach of a study on characteme, a new term that can be assigned to all the constituent parts of the characters. The word characteme has in itself, and pre-disposed as far as its meaning, a justification with the suffix -eme, which can be seen in other terms as in morpheme, phoneme, etc.

It is to be considered that a characteme is a particular component subtracted from a character by resorting first to its pictographic and rational origin; regarding other inconsistent cases with this situation, we must define characteme of certain characters by taking into account their conventional morphological compositionality. Thus, the first step to determine a characteme is to find its graphical etyma in reliable and scientific sources such as the Etymological Dictionary of Chinese Characters (Xie, 2000). For example, the character dàn, 旦, dawn, is a pictographic character composed of two components, the rì, 日, sun, and the $y \bar{l}$, 一, one, which in turns are charactemes. This is because both components are etymologically recognized with their pictorial properties, since the characteme rì, 日, sun, pictographically represents the sun while the characteme $y \bar{i},-$, one, the horizon of the earth. This example indicates 
that a simplest stroke can be a characteme, whereas the characteme defined by conventional morphological reasons requires a criterion of substitution ${ }^{3}$.

In summary, we intend, with the introduction of the concept of characte$m e$, to reconcile in this concept those different denominations of constituent parts of Chinese characters, to simplify the teaching and learning of the components of Chinese characters and, likewise, of the сСт.

\section{Neurocognitive Linguistics and Relational Network Theory}

\subsection{Neurocognitive Linguistics}

Sydney Lamb is considered the father of Neurocognitive Linguistics and his Stratificational Grammar is regarded as the predecessor of his Relational Network Theory (Lamb, 1999, 2004, 2011, 2016). There have been plenty of introductions and reviews of Lamb's theory that worth to mention (Cheng, 2001, 2002, 2005, 2006, 2011; Liu, 2007; Yang, 2007; Zhou, 2016; García, 2007, 2012, 2015; Gil, 2009). Lamb and his team also founded a website Langbrain ${ }^{4}$, which presents the core parts of Neurocognitive Linguistics Theory and provides downloads of articles and software applications.

\subsection{Relational Network Theory}

Relational Network Theory (RNT) is a connectionist theory based on Hjelmslev' glossematics (García, 2015). It contains some basic notations which can be explained by diagrams. The whole relational system has a neurological plausibility addressed in Lamb (1999, 2004, 2011, 2016), García \& Gil (2011)

3. The conventionality consists in the charactemic division of the character zuò, 作, to do. it is not difficult to recognize that the constituent parts of the first-level's division are the rén, $\uparrow$, people, and the zhà, 乍, first. Undoubtedly, the rén, 亿, people, is a very common and well-known characteme because it appears in many compound characters. As for the zhà, 乍, first, to know if it is a characteme or not, we will resort to the substitution criterion: to determine the alleged divided parts of a component as characteme, each of them must be a constituent unit of other components or characters with an etymological or conventional origin. We see that the zhà, 乍, first, can be divided into two pieces: the ${ }^{-}$(without pronunciation and meaning) and the rest of the three strokes. The latter cannot be combined with other features apart from ${ }^{\text {- }}$. So the charactemes of the zuò, 作, to do, are the rén, $\}$, people, and the zhà, 乍, first. While the latter one can form characters such as zěn, 怎, how, zhà, 炸, to explode, etc.

4. http://www.ruf.rice.edu/ lngbrain/main.htm 
and García (2012) with a strong operability. The following shows some fundamental knowledge of the system.

The most essential arguments of the RNT model consist of two major logics of human cognition: and and or, which have been developed into two nodes that function in multiple relations and, therefore, constitute the most basic connections among other elements.

\section{Figure 1}

The basic rnt nodes in compact notation

\begin{tabular}{l|l}
\hline & $\begin{array}{l}\text { Node name: downward unordered and node } \\
\text { Activation: } \\
\text { upward activation from } \mathbf{b} \text { and } \mathbf{c} \text { goes to } \mathbf{a} \\
\text { downward activation from } \mathbf{a} \text { goes to } \mathbf{b} \text { and } \mathbf{c}\end{array}$ \\
\hline
\end{tabular}

Source: Adapted from Lamb , 1999, p. 67.

The triangle represents the and nodes while the horizontal bracket represents the or nodes. The connections viewed as lines indicate the active path, that is, the relationship. All these nodes depicted above are downward nodes, represented by the arrangement of which the singular side of the line locates in the superior part of the node. Thus, it's not too difficult to understand that the activations will go from the upper sidelines to the lower sidelines, however, it doesn't imply that there will be no activations that go oppositely: from the lower side to the upper side. It can be seen that there are two structures of separated and gathered ends as the joint part between lines and nodes. The gathered ones indicate that the activated information is input or output at 
the same time meanwhile the separated ones indicate that the input or the output is ordered (from left to right). We can use the first node to illustrate how it works. It can be assumed that it is activated from the bottom-up, since the activation is input from the $b, c$ side to reach the node. Knowing that both inputs have reached a critical value required by the node, there will be an output at $a$ side. The first node in Figure 1 is downward, it will be very alike in the coordinated upward node, which means that all nodes are bidirectional. These nodes are constituents of the compact notation of the RNT. It is regarded to deal with a more concrete, direct, and integral connective system whereas the narrow notation in RNT is used to deal with a more abstract, operative system that can probably find its application in the computer field.

\subsection{Charactemes in the RNT}

The RNT model can be applied to explain the visual perception of Chinese characters although Lamb mainly concerned about its phonetic representation. By the way, it is used to interpret the relationship between phonemes and morphemes, we can adapt it to the visuospatial perception of charactemes of Chinese characters in which the connections are presented analogically, even though the visual domain requires less sequential but more spatial concerns than phonetic representation. According to the RNT, the recognition and discernment of Chinese characters can be represented by the following figures. The numbers indicated in the following two figures are numbers of corresponding strokes in a stroke table elaborated in Chen (2017b), which are of less importance since we can intuit them from the charactemes close to each vertical line between two nodes.

According to the perception figure of the character $t \bar{a}$, 他, he, it is indicated step by step the activation of this character in our visual perception from the lower level to the upper level. The and and or nodes are necessary for the activation steps in certain situations. In the upper figure, we discover that each nection ${ }^{5}$ (which is labelled by characteme or Chinese character) has mental representations to specify a Chinese character or characteme. These are labels of the fine system, which imply that neither the Chinese characters nor the charactemes have real unitary existences inside the brain, but the relational ones. In RNT, the lower level is always going towards the expression while

5. Term coined in Lamb (1999: 73). 


\section{Figure 2}

Visual perception of two Chinese characters represented by the RNT

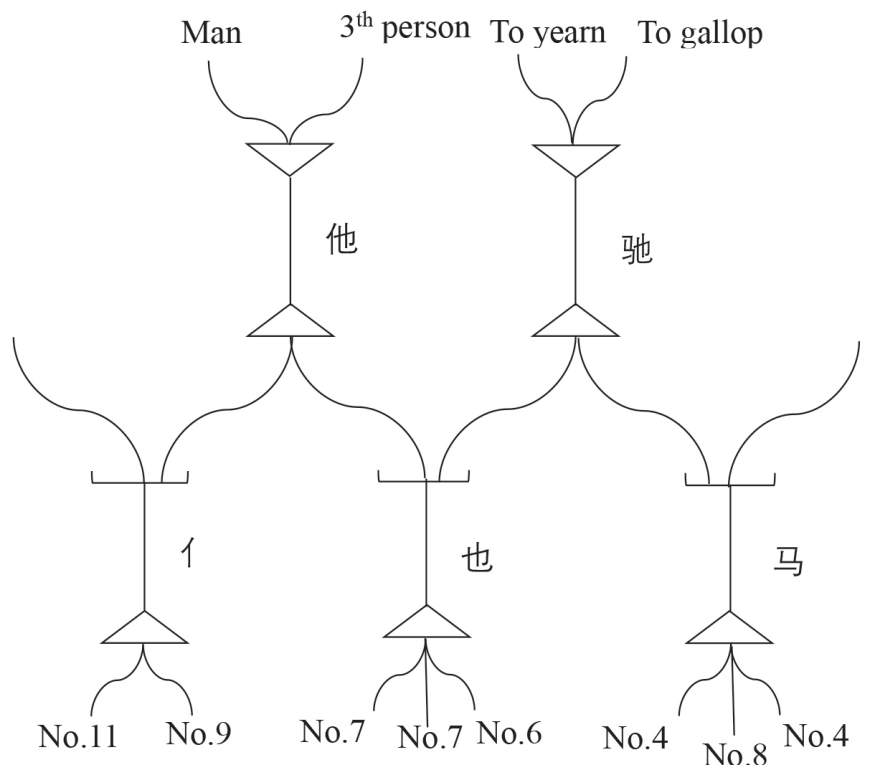

Source: Chen, 2017b, p. 232.

the higher level, towards the concept. Hence, we can specify the numerical markers, which represent their corresponding strokes, by linking them to extensive lines towards the perceptional organisms of the human being. And the upper parts of the nections of the character tā, 他, he, and the chí, 驰, to gallop, are supposedly pointed in turn to the conceptual semantics (Jackendoff, 2009; Cheng, 2011). However, the perceptional case of the characters as the transcribed model of the RNT's phonetic system is not as simple as we have described, because Lamb himself comments that even in his phonetic models many details have been eliminated, and it would be more complex to consider and draw a figure that can represent a real situation. This is imaginable and rightly so, since in our case, the visuoperceptual reality requires more systematic conditions that have not been included in the figure and one of them will require an immediate resolution: the spatial conception involved in the visual perception of Chinese characters. 


\section{Figure 3}

Visual perception of two Chinese characters represented by the RNT (with visuospatial features)

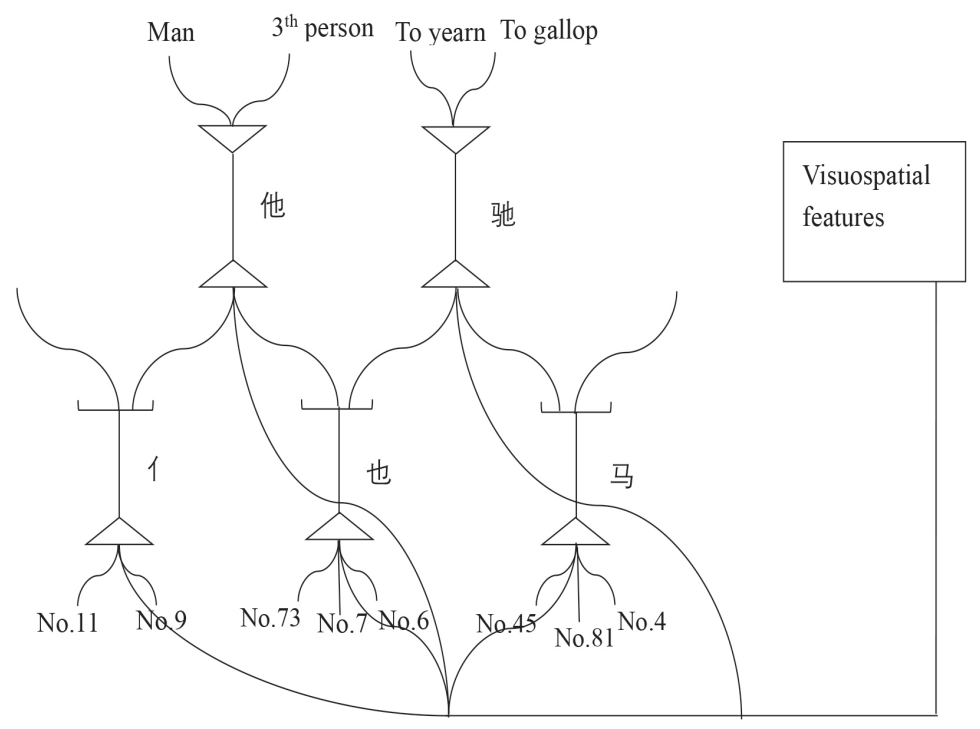

Source: Chen, 2017b, p. 233.

In Figure 3, it can be deduced that all the nodes and are unordered because they do not have the linear order as indicated in phonetic models. Apart from the connections with their corresponding ones of the upper and lower level, they are connected to a bidimensional domain labeled by visuospatial features, which contains the spatial rules about the position and more detailed features of the stroke and component's patterns. It will solve the problems of the spatial conception of Chinese characters in the system: probably an alternative of the order or unorder connections in the compact notation. The linear or bidimensional "orders" illustrated here may not apply to homological parts as the temporal order of the spoken language discussed in the and and or nodes of phonetic models since the temporal one is more abstract and cannot be observed directly. With the module of the conceptual part of the brain, which is connected at the same time both with the visuoperceptual and phonological system, it would be easier to explain the connections we have of the two characters, and obviously with redundancy. Certainly, the nections of 
the lower part represented by combinations of strokes require more complex spatial concepts than simple linear ones: e.g., strokes in the characteme rén, 亿, people, the yě, 也, also, the $m a \check{, ~ 马, ~ h o r s e, ~ e t c . ~}$

\section{Components teaching in the CCT}

In the ambit of the CIT, very few textbooks pay specific attention to the СCT. Furthermore, currently, the ССт is mainly based on traditional methods. It should be clarified that the resurrection or emphasis on the research of components by the academic community has already started to rethink the teaching methods of the сст. At the theoretical and analytical level, there have been studies of Chinese characters through Gestalt theory (Gu, 2013), error analyses of students' handwriting and the studies of the components of Chinese characters, so far as to conduct some discussions of the mistiest concept that is considered the Grapho-Morphological Awareness (GMA) of Chinese characters, known as zìgăn, 字感. Regarding the last concept, we propose a relatively not misty explanation: viewed from a neurocognitive perspective, zìgăn can be recognized as a synthetic visuoperceptual and cognitive conceptualization that a person has developed toward Chinese characters by undertaking their visuospatial discernment, decipherment, memorization, etc., which can be interpreted by RNT (including the audiovisual, motor system, etc.), because it is a rigorous connectionist network in terms of the establishment of abstract relationships inside the brain. The zìgăn understood in this way is a complex network in which almost all the brain capacities related to the Chinese characters can be included, but we limit ourselves to describing it just in the visual system since it is an initial and important stage to know the basic visuospatial processing issue on Chinese characters, moreover, to analyze the charactemes of the characters, both their spatial position and their structure. Therefore, all the discussion we have done will become new directions that require attention in the ССТ if it is combined with Ausubel's Meaningful Learning Theory (MLT).

\subsection{Ausubel's Meaningful Learning Theory}

To apply the studies of characteme to the CCT, we'd like to incorporate the Meaningful Learning of Ausubel (Ausbel, Novak, \& Hanesian, 1983) into a plausible proposition of teaching methods. 
Meaningful Learning (ML) focuses on the internal and cognitive structure in each individual and the learning process can be understood as an interaction between the most relevant knowledge of that structure and new information so that it acquires a meaning within it and will be integrated later.

The substantive aspect of ML indicates that the learning consists in incorporating the organizational essence of new information, regardless of what is superficially described, for example, expressive words. While the non-arbitrary means a selective relationship that can be established between the new information and the cognitive structure of the subject. This means that the idiosyncrasy of both the cognitive base of an individual and the new knowledge has a variability, whose objective is interpreted in that they are reorganized to become a newly variable set, ready to welcome new integrations.

\subsection{Collaboration between the characteme teaching and mlt by the RNT}

The Ausubelian theory emphasizes the pre-existing cognitive structure of the students in the learning, which means that it has also emphasized the importance of autonomy and spontaneity on the part of the students.

\subsubsection{Teaching of basic charactemes}

The characteme-teaching of Chinese characters should occupy the first pages devoted to the CCT, while the application of the Gestalt theory, without doubt, has taken a significant step forward in this field since it has proposed a solution to the "misspellings" committed by foreign students (Chen, 2017b).

The teaching of basic strokes of Chinese characters is essential in the didactic process. Some of them have also been considered as basic charactemes. It is very important to be clear about the meaning of charactemes. In this case, the teacher must explain it in the first class. For foreign students it will be easy to understand what a characteme means since the concept is comparable to any minimum unit in both the phonetic and morphological fields.

After introducing the fundamental meaning of characteme, the teacher can present the first characteme-strokes to the student following the principle of assimilation of ML (Ausbel, Novak, \& Hanesian, 1983). This will be based on an analogical explanation between some basic charactemes and the subsunsor ones (Ausbel, Novak , \& Hanesian, 1983) of the pre-existing cognitive structure of the student. We must not forget the metaphorical 
reference that some charactemes have, which can also be interpreted by the Ausubelian theory since the metaphorical process can be compared with the process of the interaction between the subsunsor and the new information. For example, in the case of the character $y \bar{i}$, 一, one, we will see what are the points of knowledge that must be taken into account in ML and how the RNT model is used to explain this process. But as in general, let's take a look at the module of the character dă, 打, to hit.

\section{Figure 4}

Visual perception of the character dă, 打, to hit, by the RNT

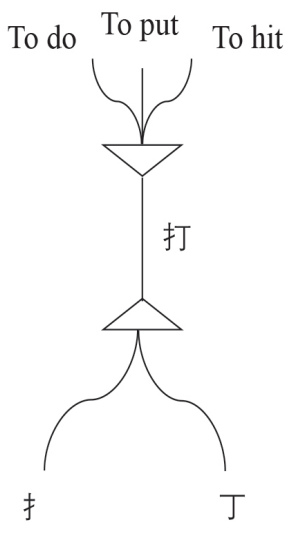

Source: Chen, 2017b, p. 370.

According to the RNT, in the inferior part of the node model, the perceptible elements for the subject are presented. In the case of the character dă, 打, to hit, we see that the lower level is composed of two charactemes: the shǒu, f, hand, and the ding, 丁, man. Obviously this diagram is only a part of the visual perception system of the character dă, 打, to hit, since its lower part can be extended to the extreme where the perception of each detail of this character is explained. Also we realize that the core of this character (to be ideal) does not have any particular style, that is, it is limited to being a label, and the concrete content of the label, if it is insisted on materializing it, varies by under each person. So, the ML of this character dă, 打, to hit, occurs only when presented. This unit composed of two charactemes is dismantled and these are related to the pre-existing subsunsors that we already have here: 
the characteme shoru, f, hand, and the characteme ding, 丁, man. Thus, the production of an ML of the new character is explained in the RNT model that highly abstracts the internal topographic mechanism of our mind. Having explained it, we will see how the character $y \bar{l}$, 一, one, is learned.

\section{Figure 5}

Visual perception of the character $y \bar{i},-$, one, by the RNT

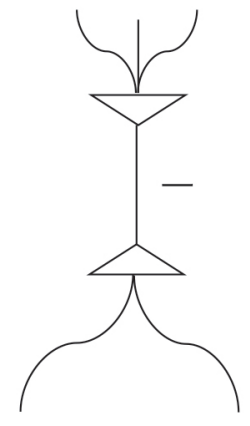

Source: Chen, 2017b, p. 371.

Undoubtedly, in the learning of characteme, it is not necessary to resort to its composition with other charactemes or strokes. Therefore, while considering only the nodal unit of this characteme, the nodes and, at both ends, are required. However, if we consider this characteme in composition with more components or characters or other things, it will be the node or that is in the upper part of the nection. Anyway, we will pay attention to the details of both parts to understand better this nection and see how an ML is done by taking it into account.

\section{Figure 6}

Inferior part of the visual perception of the character $y \bar{\imath}$, , , one

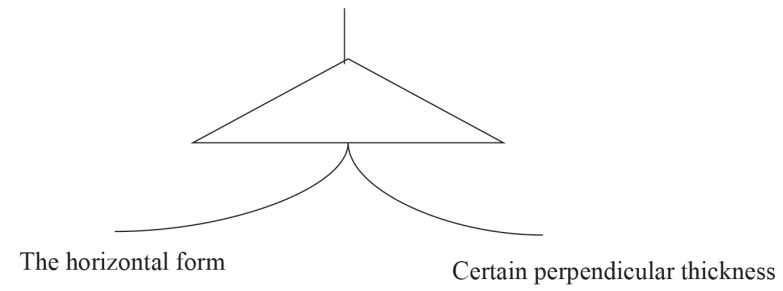

Source: Chen, 2017b, p. 372. 
This is the amplified lower part of the nection of the character $y \bar{z}$, - one, which apparently has two branches at least for the frank visual perception of the physical features of this characteme-stroke. The subject will first perceive both its form and its thickness, which are considered as two elements of the new information. The stimulus activated by this vision of the manifested characteristics rises to the upper part of the connection through the connection between both parts that is to be reinforced, that is, once this connection is formed, for its memorization, more activation forces or weights are required.

\section{Figure 7}

Superior part of the visual perception of the character $-y \bar{n}$, one

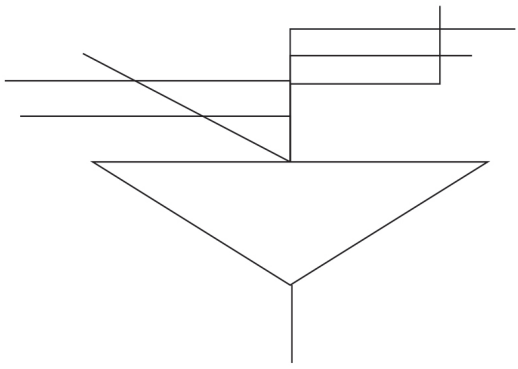

Source: Chen, 2017b, p. 372.

The upper part has a very important role in the ML since it deals with the semantic part of the visual perception. In this figure, we see that there are several extensions upwards from the triangle node, which means that the stimulus coming from below can be connected to many semantic terminals, which in this sense, are probable subsunsors that are part of the pre-existing cognitive structure of the subject. Each of the extensions is connected to a pre-existing individual concept and, for this reason in the figure, its branches are not detailed. The concepts that the student already has conceived in the cognitive structure can be several and depend on their cognition or life experiences: a trunk, the horizon of the earth, a loaf of bread, the edge of a book, a pencil, a stick, etc. These objects go along with their graphic idiosyncrasies. Any of them can be used as a subsunsor device to convey the units perceived in the lower level of the physical world, and to get ready to incorporate new information to constitute new ones. Despite the universal 
semantic elements connected to the nection, it will be possible to explain some cases during the ML. If the student has pre-conceived the shape of a trunk, for example, when the characteme-stroke $y \bar{i}$, 一, one, is presented, he will see that its shape coincides with the morphological structure of the image of a trunk that he himself knows. In this sense, it is not a specific trunk, but any trunk, or rather, a prototypical trunk. To continue, the morphological assimilation is produced, as with the interaction (A'a') (Ausbel, Novak, \& Hanesian, 1983) between the subsunsor, the concept of trunk (A') that, affected by the conceptual integration of the new information, is no longer in its initial state (A), and the concept of the characteme-stroke $y \bar{i}$, - one (a') that, affected by the subsunsor ( $\left.\mathrm{A}^{\prime}\right)$, is no longer with its initial state (a). The ML, in this case, occurs when the concept of the characteme-stroke $y \bar{l},-$, one, is acquiring a relevant interaction with the concept of trunk, of which the subject, when presented with the characteme-stroke, can refer to the trunk, and when presented with the trunk, he can refer to $y \bar{l}$, 一 one. This interactive set (A'a') will then remain in the process of obliterating assimilation (Ausbel, Novak , \& Hanesian, 1983) and will come out in a new, consolidated set, ready for learning, becoming a new subsunsor ( $\left.\mathrm{A}^{\prime}\right)$.

In this process, the teacher must be aware of the pre-existing knowledge of their students. It means that he/she does not have to enter abruptly into the explanation of the characteme $y \bar{i}$, - one, and it does not imply a gradual introduction, which is less significant. He/She can present the brief introduction by means of questions, showing several images of familiar figures (although it's also convenient to consider the metaphorical method as a specific way in ML because they share a lot in common): e.g., which one is more similar to the characteme or what is the common characteristic among them. Or it is possible that he or she can simply present a relatively complicated character for asking what is the simplest characteme at first sight and what it looks like, intending to encourage the meaningful acquisition of new information. The fact of proposing examples during teaching should be amenable to students. While they are very motivated to establish spontaneously meaningful relationships while learning this characteme, they can voluntarily avail themselves of any explanation that makes the implication both morphological (denoting a horizontal form) and semantical (which encompasses the meaning of being horizontal). 


\subsubsection{Teaching of Charactemic variants}

In the characteme list presented in Chen (2017b) subtracted from 800 Chinese characters there are many variants of charactemes. As we see in 4.2.1, all the basic charactemic units can be explained in that way according to their graphic idiosyncrasy. The teacher is required to find an appropriate but meaningful way to achieve this goal. The objective of the meaningful teaching of Chinese characters is that students develop a stable state of their memorization and operational ability. Regarding the learning of the variants of a certain characteme, it is recommended that it be carried out considering it a common characteme and it can also be taken as new information concerning to its antecedent, made in turn as a subsunsor. For example, the ML of variants of the charactemes rén, 人, people: rù, 入, to enter, $b \bar{a}$, 八, eight, wŭ, 人, Х, five, and $y i$, X, to rule. If the teacher prefers to explain them by looking for subsunsors under the principle just described, it will be an appropriate method. If the characteme-character rén, 人, people, is already a meaningfully learned unit, the teacher may carry out the teaching of those variants considering the character rén, 人, people, as subsunsor. However, the rule used to determine the variants of a characteme does not start from the semantic base, so teaching can only be done in the morphological realm of the characteme-character rén, 人, people. And the RNT scheme of this kind can be illustrated without entering into the semantic field of these pieces:

\section{Figure 8}

Primary scheme of visual perception of the characteme rén, 人, people, by the RNT

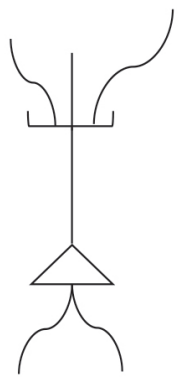

Source: Chen, 2017b, p. 374. 
This model does not specify the label of the nection that can be any of the variants of the characteme-character rén, 人, people. To determine it, we must add the "visuospatial features" as we have indicated in 3.3 on visual perception. With this model, we can understand that it is a mere combination of two lines that are perceived in its lower level, which are two strokes diagonally opposed to each other. And we must also pay attention to the small changes of outline that are distinguished, and it would be more complicated to consider. The stimulus is done by perceiving the two basic strokes and then going upward. The superior part could be amplified:

\section{Figure 9}

Superior part of the visual perception of the primary scheme

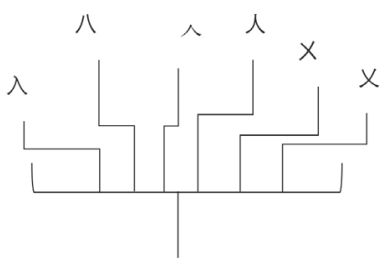

Source: Chen, 2017b, p. 375.

We see, then, that this structure derived from the RNT model indicates the possible charactemic compositions that vary with the base of two strokes. The chosen node is the or upwards since it is a conditioned connection that goes upward, selected for its determined activation. Using this model, one can perform an ML with the previously learned characteme-character rén, 人, people, which is also included in this scheme as a subsunsor, while other variants, new information, will be learned meaningfully through the assimilation and the obliterating assimilation. This is how the charactemic variants are learned.

\subsubsection{Teaching of compound charactemes}

After the explanation of the ML of simple charactemes, it will be easier to analyze the more complicated charactemes. This is a very important issue because the majority of charactemes are compound ones which have more complex structures. The teaching of these charactemes can also initiate in two ways: first, using grapho-morphological methods, that is, the teacher looks for 
some analogous images for the understanding of the charactemes in question, since they are mostly meaningful; the second way is as the same as learning the variants of characteme, that is, through learning basic charactemes. In the latter method, the learning process would fall into two directions: the teacher is responsible for the teaching or the student will undertake the ML task on their own.

A compound characteme can be composed of two or more simple charactemes. It is worth asking, in this case, why is it not subdivided into charactemes of fewer strokes? This is because these composite features represent in themselves a complete meaning although, apparently, can be subdivided into two simpler charactemes at least. The tián, 田, field, for example, a five-stroke characteme, represents perfectly the arable land, which can form characters such as qí, 畦, country section, diàn, 钿, filigree, pàn, 畔, side, jiè, 界, border , etc. While it seems to be composed of two simpler charactemes: the kǒu, 口, mouth, and shi, 十, ten. They are charactemes of the characters chàng, 唱 to sing, xià, 吓, to frighten, chì, 吃, to eat, shé, 舌, tongue, xiōng, 兄, elder brother, etc, and gŭ, 古, ancient, xié, 协, to help, zhí, 直, straight, bó, 博, wise, wǔ, 午, midday, etc., since in these characters they are the minimum significant units.

The ML process of the compound charactemes consists in considering the simple ones, which can serve for the memorization of the compound ones. Once the structure of the compound charactemes has been memorized, the student will also look for ways to memorize their meaning. They can resort to the help of the teacher or simply memorize what they mean in corresponding characters, because at this stage of learning, they must have learned some simple charactemes and several compound ones as well, which helps them to self-determine the organizational mechanism that the zìgan can depict, that is to say, a pre-existing knowledge of learning Chinese characters, a new character subsunsor. For example, the character mĭ, 米, rice, although it is a characteme-character with six strokes, which can be considered as a compound characteme, the student can analyze it via simple charactemes after learning the $b \bar{a}$, ’, eight, shí, 十, ten, $b \bar{a}$, 八, eight, or simply the $b \bar{a}$, ’, eight, mù, 木, wood. For such kind of learning, the RNT schemes are structured in this way: 
Figure 10

The RNT schemes for the learning of compound charactemes
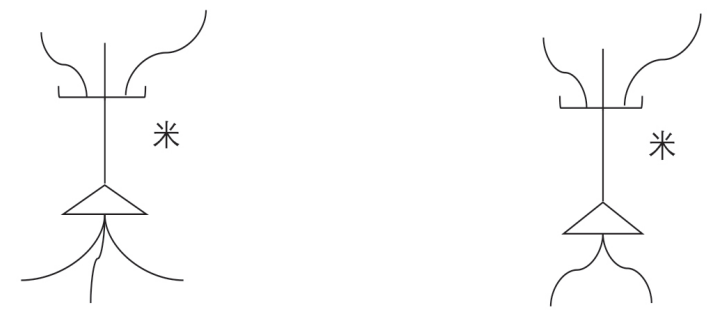

Source: Chen, 2017b, p. 376.

If it is about characteme learning, the superior parts must be a node or upwards since it is connected to the composition of characters. The lower parts are composed of three charactemes or by two charactemes due to the spontaneous visual perception of the student, and the upper parts are connected with at least three lines, of which each one represents a position that occupies the characteme in the character. For example, on the left side: the characters $c \bar{u}$, 粗, robust, fěn, 粉, powder, gāo, 糕, paste, lì, 粒, grain, etc.; in the superior position: lèi, 类, race, lín, 粦, phosphorus, etc.; in the inferior position: liáng, 粱, sorghum, sù, 粟, cereal, di, 㐘, buy cereal, etc.

Explained by the MLT, it is comprehensible that two or three simple charactemes can be regarded as subsunsors (A), whose joint formation in one piece can be considered as (A'), while the characteme mĭ, 米, rice, the new information (a), simply connected with the three or two charactemes to become a modified unit in the learning ( $\left.\mathrm{a}^{\prime}\right)$. So the ML, after a process of obliterating assimilation, remains only with the learning of $m \check{l}$, 米, rice, which is in turn to become (A').

\section{Conclusions}

The above discussion indicates that the division of Chinese character into components is relevant in the ССт, and the introduction of the concept characteme, along with the $\mathrm{ML}$, not only provides a theoretical support for the ССТ, but also a more scientific resolution for components teaching.

The RNT of Neurocognitive Linguistics provides a theoretical basis for the visual perception of Chinese characters. In addition to the discussion of 
visual, auditory, and motor perception, Neurocognitive Linguistics hopes to elucidate the connections of all brain activities through the relational networks although it is striving for a computerized application with its plausibly achieved fineness. Therefore, the analysis of the visual perception of Chinese characters helps to amplify the research ambit in concern with the visual perception. Furthermore, we also need to combine theoretical research with empirical research to achieve a two-pronged approach and complement each other with the already high plausibility of the RNT theory (García, 2012). According to the theoretical study, we are looking forward to develop the empirical study of characteme acquisition. To make a difference, we hope that the proposed concept will become a unified experiment subject, and the research on the Chinese character components which it belongs to will become a major subject for the basic study of the visual perception of Chinese characters and the CIT.

\section{References}

Ausubel, D., Novak \& Hanesian. (1983). Psicología Educativa: Un punto de vista cognoscitivo. (2 ed.). México: Trillas.

Bai, J. B. \& Liu, Y. N. (2006). 试论非汉字文化圈学生的字感培养与获得 [The acquisition and cultivation of students' zìgăn outside the circle of Chinese culture]. 语言教学研究 [Journal Study of Language], 5, 104-105.

Chen, H. (2015). ¿Ideogramas o pictogramas? Una introducción a los caracteres chinos. México y la Cuenca del Pacífico, 4(10), 107-129. doi: 10.32870/ mycp.v4i10.479

Chen, H. (2017a). La metáfora y los caracteres chinos, México y la Cuenca del Pacífico, 6(16), 143-165. doi: 10.32870/mycp.v6i16.539

Chen, H. (2017b). Enseñanza de los caracteres chinos a los estudiantes hispanohablantes: desde una perspectiva de la ciencia cognitiva (Tesis doctoral). Universidad de Complutense, Madrid, España.

Chen, H. (2018). Crisis de los caracteres chinos. Círculo De Lingüística Aplicada a La Comunicación, 74, 29-44. doi: 10.5209/CLAC.60512

Cheng, Q. L. (2001). 认知语言学概论 [Introduction to Neurocognitive Linguistics]. Beijing, China: 外语教学与研究出版 [Foreign Language Teaching and Research Press].

Cheng Q. L. (2002). 逼近语言系统 [Approach to the Linguistic System. Nanjing]. 东南大学出版社[China: Southeast University Press]. 
Cheng, Q. L. (2005). 神经认知语言学引论 [An Invitation to Neurocognitive Linguistics]. 外文出版社 [Beijing, China: Foreign Languages Press].

Cheng, Q. L. (2006). 概念框架和认知 [Conceptual Frame and Cognition]. 上 海外语教学出版社 [Shanghai, China: Shanghai Foreign Language Education Press].

Cheng, Q. L. (2011). 概念语义研究的新视角 [A New Approach to Conceptual Semantics]. 外语教学与研究出版社 [Beijing, China: Foreign Language Teaching and Research Press].

García, A. M. (2007). Methodological Tenets, Plausibility and Reality in Chomskyan Biolinguistics. Linguistics and the Human Sciences, 3(3), 303324. doi: 10.1558/lhs.v3i3.303

García, A. M. (2012). La Teoría de Redes Relacionales: correlatos neurológicos de un modelo lingüístico conexionista. Onomázein, 26(2), 221-257.

García, A. M. (2015). A connectionist approach to functional-cognitive linguistics: Spanish pronominal clitics and verb endings in relationalnetwork terms. Revista Signos. Estudios de lingüística, 48(88), 197-222. doi: 10.4067/S0718-09342015000200003

García, A. M. \& Gil, J. M. (2011). A historical survey into the origins of Lambian linguistics. LACUS Forum, 36, 111-123.

Gil, J. M. (2009). Neurología y lingüística: la "teoría de redes relacionales" como una alternativa ante Chomsky. Revista de Investigación Lingüística, 12, 343-374.

Gu, Z. X. (2013). 格式塔心理学理论指导下的整字教学 [Enseñanza de los caracteres enteros dirigida por la teoría psicológica de la Gestalt]. Yangzhou, China: Universidad de Yangzhou.

Jackendoff, R. (2009). Conceptual semantics and cognitive linguistics. Cognitive Linguistics, 7(1), 93-129. doi:10.1515/cogl.1996.7.1.93

Lamb, S. (1999). Pathways of the brain: The neurocognitive basis of language. Amsterdam: John Benjamins.

Lamb, S. (2004). Language and Reality. London: Continuum Books.

Lamb, S. (2011). Senderos del cerebro: la base neurolingüística del lenguaje. (Trad. Gil, J. M. \& García, A. M.). Mar del Plata, Argentina: EUDEM.

Lamb, S. (2016). Linguistic structure: A plausible theory. Language Under Discussion, 4(1), 1-37.

Liu, Y. H. (2007). 语言的神经基础 [Neurobasis of Language]. 中国社会科学 出版社 [China social sciences press]. 
Marcos, N. (2010). Grapho-morphological awareness in Spanish L2 reading. (Master's thesis). Pittsburgh University, Pittsburgh.

Sánchez, C. H. (2013). Priming morfológico y conciencia morfológica: Una investigación con estudiantes norteamericanos de E/LE (Tesis doctoral). Universidad de Salamanca, Salamanca, España.

WU, L. W. (2014). A reconsideration of 2,905 Chinese characters' component disassembly in the Chinese characters of HSK Graded Outline, TFM. China: Guangxi University.

Xie, G. H. (2000). 汉字字源字典 [Etymological Dictionary of Chinese Characters]. Beijing, China: Peking University.

Xu, S. (1963). 说文解字 [Shuowenjiezi]. 中华书局[Beijing: Book Company Zhonghua].

Yang, Y.M. (2007). 语言的理论假设与神经基础一一以当前汉语的若干 神经语言学研究为例 [Theoretical Hypotheses on Language and Their Neurological Basis]. 语言科学 [Linguistic Science], 6(2), 60-83.

Zhou, P. (2016). 认知神经语言学方法论模型的建构 [A Methodological Model for Cognitive Neurolinguistics]. 外国语 [Journal of Foreign Languages], 39(2), 39-47. 